\title{
CHIPS: Monitoring Colonias Along the United States- Mexico Border in Texas
}

Colonias, which are unincorporated border settlements in the United States, have emerged in rural areas without the governance and services normally provided by local government. The expansion of colonias in the United States-Mexico border region can be traced to the rapid growth associated with the Mexican Border Industrial Program during the 1960s. This rapid population growth created a lack of affordable housing, causing new migrants in the United States to purchase rural homestead lots through a contract-for-deed program from land developers. Because of the need to keep prices affordable and the absence of effective land-use controls, these homesteads expanded into rural subdivisions, commonly called colonias, without proper infrastructure. Colonias have been identified in the four U.S. border states, with Texas having designated the majority, which numbered over 1,400 colonias in 2001. Because the region is binationally interconnected economically, politically, and socially, the phenomenon of colonias in the United States is a transborder issue.

Because colonias are dynamic in nature and not uniquely represented within the census geography, an explicit long-term working database is needed to monitor progress, set infrastructure priorities, and measure quality-of-life indicators within the colonias. The U.S. Geological Survey (USGS), in collaboration with the U.S. Department of Housing and Urban Development, Office of the Texas Attorney General, Office of the Secretary of State, and Texas Water Development Board, developed the Colonia Health, Infrastructure, and Platting Status (CHIPS) tool. CHIPS is a relational database that contains the current infrastructure (water, wastewater, roads), platting, and health care information for colonias in the six Texas counties with the highest number of colonias. These counties are Cameron, El Paso, Hidalgo, Maverick, Star, and Webb. The powerful CHIPS report generator ranks each colonia based on its level of infrastructure development in relation to its health risk. To help cities along the United States-Mexico border manage issues related to colonias growth, CHIPS is publicly available through the USGS U.S.-Mexico Border Environmental Health Initiative website

http://borderhealth.cr.usgs.gov/datalayers.html under the selection category of "Places (Names)"

The criteria for the health classification are based on the status of their infrastructure as identified by the Texas Senate Bill 827 Workgroup (table 1).

Table 1. Classification criteria for colonias.

\begin{tabular}{|c|c|c|}
\hline $\begin{array}{l}\text { Degree of } \\
\text { health risk }\end{array}$ & $\begin{array}{l}\text { Classification } \\
\quad \text { level }\end{array}$ & Criteria \\
\hline \multirow[t]{4}{*}{ High } & Red & At least one of the following applies: \\
\hline & & 1. Either all or some lots have inadequate wastewater disposal (cesspools) \\
\hline & & 2. All lots do not have potable water supply \\
\hline & & 3. Not platted \\
\hline \multirow[t]{5}{*}{ Medium } & Yellow & $\begin{array}{l}\text { Platted colonias with a potable water supply and adequate wastewater disposal, and at least } \\
\text { one of the following applies: }\end{array}$ \\
\hline & & 1. Either all or some lots lack solid waste disposal (trash collection) \\
\hline & & 2. Not all roads are paved \\
\hline & & 3. Not all roads are passable in all weather conditions \\
\hline & & 4. Floods occur during precipitation \\
\hline \multirow[t]{8}{*}{ Low } & Green & All of the following apply to all lots: \\
\hline & & 1. Platted \\
\hline & & 2. Have potable water supply \\
\hline & & 3. Have adequate wastewater disposal \\
\hline & & 4. Have solid waste disposal \\
\hline & & 5. All roads are paved \\
\hline & & 6. All roads are passable in all weather conditions \\
\hline & & 7. Does not flood during precipitation \\
\hline
\end{tabular}




\section{EXPLANATION}

Green colonias-Platted colonias with potable water supply, adequate wastewater disposal. adequate trash collection, paved roads that are passable in all weather conditions, and adequate drainage

Yellow colonias-Platted colonias with potable water supply and adequate wastewater disposal, but without either adequate trash collection, unpaved roads, or adequate drainage

Red colonias-Colonias either are unplatted, have inadequate potable water supply, or have inadequate wastewater disposal

Unknown colonias-Colonias lacking enough information to he classified

Total colonias-All colonias including green, yellow, red, and unknown types
TOTAL NUMBER AND PERCENTAGE OF COLONIAS IN SIX TEXAS COUNTIES (Cameron, El Paso, Hidalgo, Maverick, Starr, and Webb Counties)

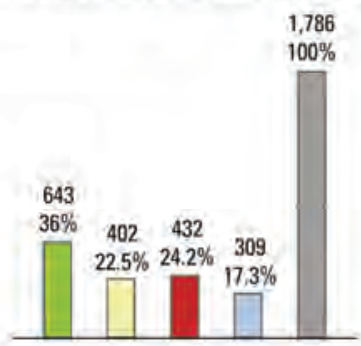

PERCENTAGE OF COLONIAS

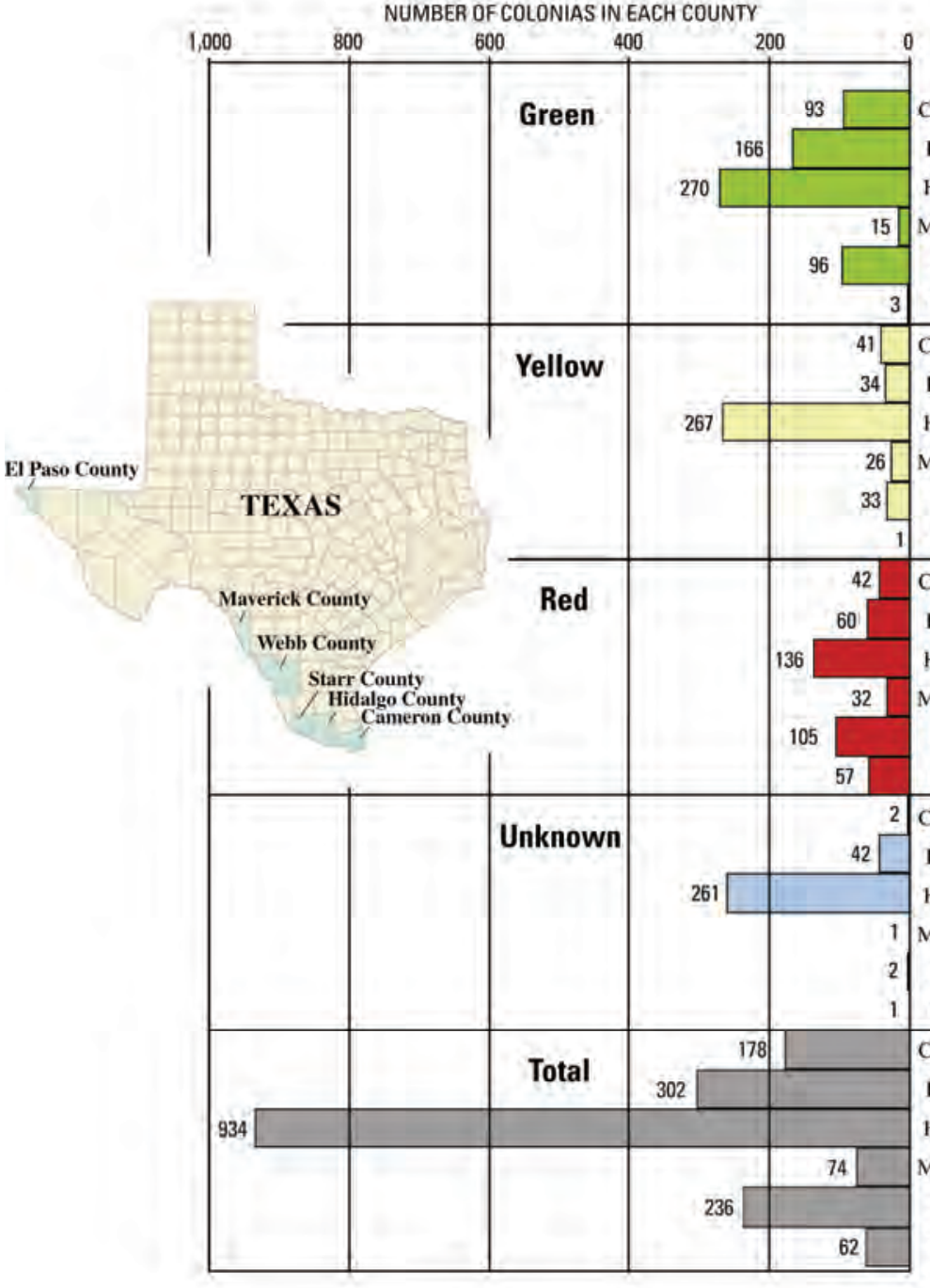

0

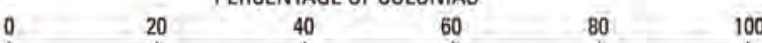

100

Caneron

Hidalgo

Starr

Webb

Cameron

El Paso

Hidalgo

Maverick

Starr

Webb

Cameron

El Paso

Hidalgo

Maverick

Starr

Webb

Cameron 0.6

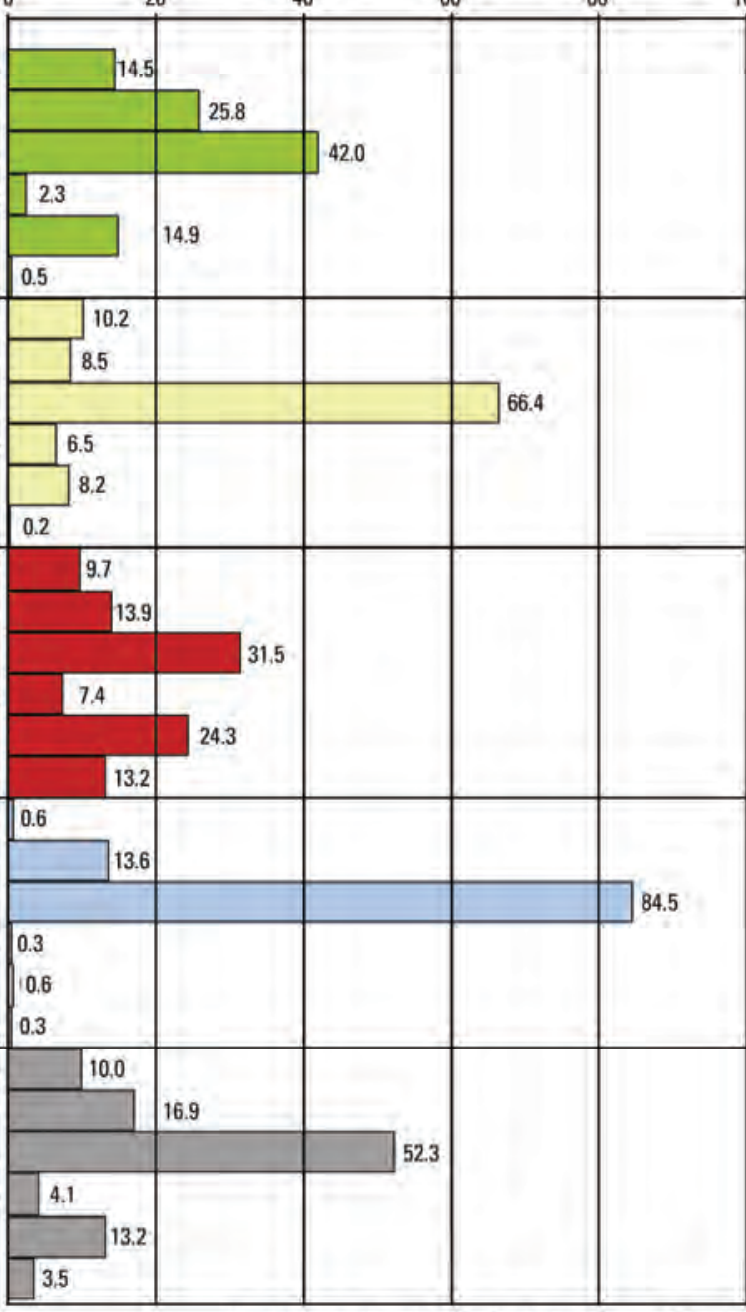

Numbers based on the U.S. Geological Survey's Colonia Health, Infrastructure, and Platting Status tool, 2006

Figure 1. Distribution of colonias by color classification associated with health risk for the six counties contained in the Colonia Health, Infrastructure, and Platting Status (CHIPS) tool. 


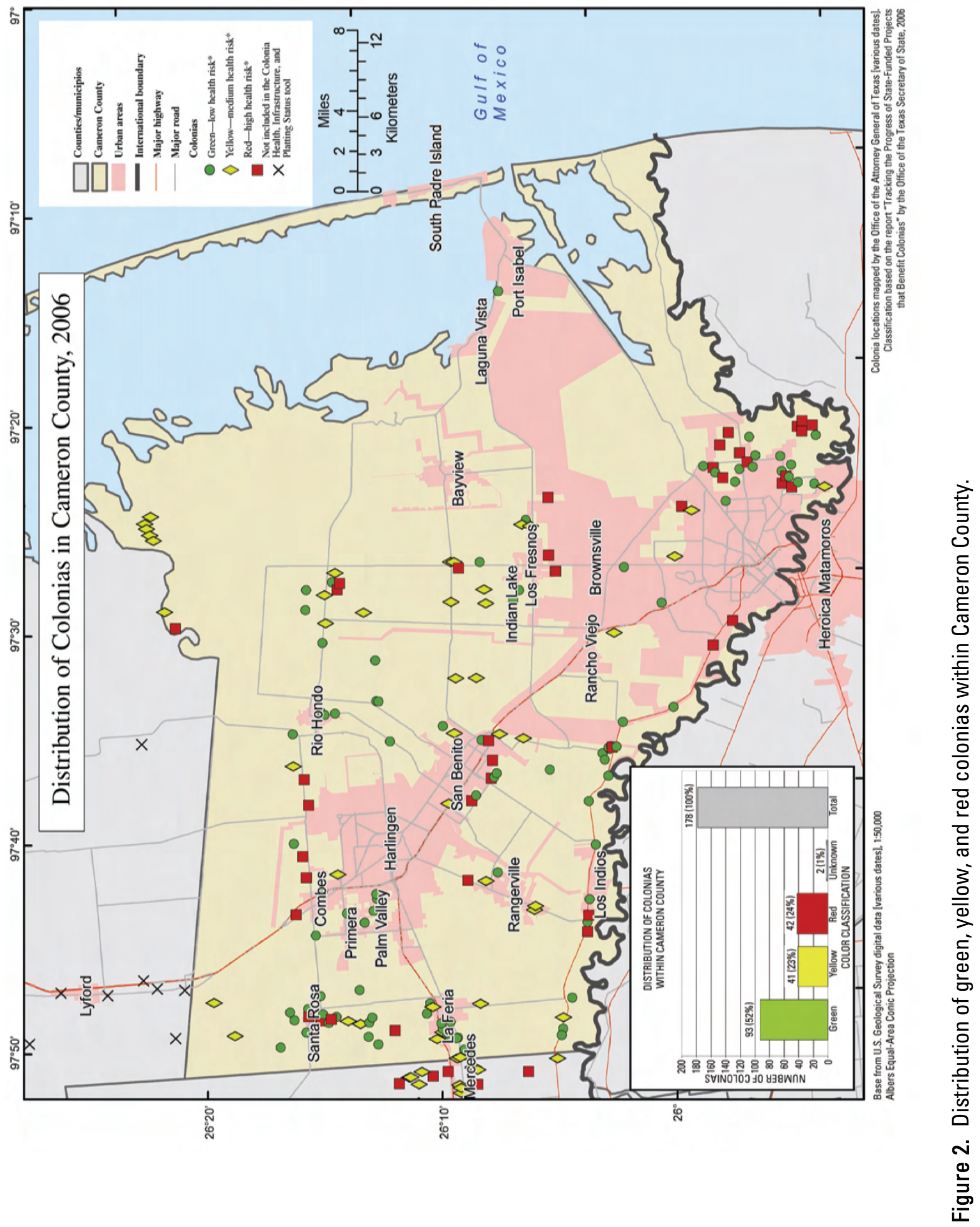


With the passing of Texas Senate Bill 827 in 2005, the State was mandated to create a colonia identification system and to track the progress of State-funded colonia improvement projects. This workgroup effort was spearheaded by the Office of the Texas Secretary of State Colonias Initiative, with collaboration from various State agencies and Secretary of State colonias ombudsmen. The existing Texas Water Development Board colonia identification system based on a unique eight-digit code was adopted. To track the progress of State-Funded projects, the Senate Bill 827 Workgroup created a set of infrastructure, demographic, and health-related criteria for the ombudsmen to collect in the six counties. These criteria were grouped into five sections (identification, platting, infrastructure, access to and information about health, and financial availability) that aided in classifying colonias by the degree of health hazard that they pose, as well as track the overall progress of State-funded projects that have benefited colonias within 62 miles of the border. The ombudsmen collected data from a variety of sources, including site visits, utility companies, county appraisal districts, and the Office of the Attorney General of Texas.

The classification criteria created by the Senate Bill 827 Workgroup served as a template for the CHIPS database schema. CHIPS uses a relational database to house the colonias data, which provides many benefits. Date entry rules and drop-down menus facilitate data entry within a graphical user interface for rapid data entry, data integrity, and quality control. The data are stored in a format that is easily updated and capable of generating custom reports rapidly. Based on the health classification criteria as determined by the Senate Bill 827 Workgroup, CHIPS classifies the colonias at three levels of health risk: high, medium, and low. As new data are entered, CHIPS can update the color classification of every colonia with a click of a button. CHIPS has a custom report generator that allows users with little or no knowledge of database queries to extract information with ease. The report generator is flexible and its output can be tailored to be either broad or specific. For example, a congressman could use CHIPS to list colonias with wastewater issues in a specific county, whereas a health researcher could list all colonias without clinical access.

The color classification of the colonias, which is based on health and infrastructure criteria provided by the Senate Bill 827 Workgroup, is fully automated by CHIPS. CHIPS determines which colonias are red, yellow or green by evaluating the colonia data populated by the ombudsmen. The results of this classification display the distribution of the colors among the counties included in CHIPS (fig. 1). Of the 1,786 colonias identified in CHIPS, 36 percent are classified as green: platted, with adequate water services, adequate wastewater disposal, adequate solid waste disposal, paved roads that are passable in all weather conditions, and adequate drainage. The percentage of colonias classified as green is higher than the percentage of colonias identified as red (24.2 percent) or yellow (22.5 percent), but still less than the combined percentage of red and yellow colonias (46.7 percent). The report generator of CHIPS allows a quick comparison of the distribution of colonias between counties. For example, 10 percent of the total number of colonias are located in Cameron County, but Cameron County has 14.5 percent of the total number of green colonias. On the other hand, Maverick County has 4.1 percent of the total number of colonias but only 2.3 percent of the total number of green colonias. The results generated by CHIPS highlight where funds for colonia projects might be needed. In addition to the spatial distribution of the colonias, the maps also display the numerical distribution of the green, yellow, and red colonias in a locational context (fig. 2). The CHIPS tool has been used to identify areas of high health risk and areas needing transportation assistance during a disaster, as well as to grant estimates for infrastructure improvements.

Texas legislation indicates a strong need to track infrastructure, health, and quality-of-life indicators for colonia residents. This tracking system needs to measure performance of financial expenditures against actual improvements and provide a method to determine future priorities. CHIPS provides an excellent tool for determining infrastructure priorities to direct future funding. The output reports provide the information needed for planning and funding purposes. The maps and graphs created from the CHIPS database provide an intuitive manner to compare the distribution of red, yellow, and green colonias between counties, as well as within counties. The statewide colonias eight-digit code identity system provides a method to link other State agency databases to each individual colonia. Thus other agencies can maintain their own working database and link the information to CHIPS as needed for reporting purposes.

The USGS Open-File Report, "CHIPS: A New Way to Monitor Colonias Along the United States-Mexico Border" has additional information on the CHIPS database, report generator, and maps. It is available at http://pubs.usgs.gov/ of/2007/1230/

\section{For more information, please contact:}

Jean Parcher, jwparcher@usgs.gov U.S. Geological Survey

8027 Exchange Dr.

Austin, TX, 78754

(512) $927-3523$

\section{U.S.-Mexico Border Environmental Health Initiative}

The colonias data can be viewed within a geographic context from the USGS U.S.-Mexico Border Environmental Health Initiative (BEHI) at http://borderhealth.cr.usgs.gov. The BEHI describes, documents, and depicts environmental quality along the U.S.-Mexico border through integration of U.S. and Mexican datasets. This site includes an Internet Map Service, data download page, current status maps of data holdings, and documented methodology for harmonizing scientific datasets at various scales across international borders.

Any use of trade, product, or firm names is for descriptive purposes only and does not imply endorsement by the U.S. Government. 